\title{
Weight loss maintenance in women two to eleven years after participating in a commercial program: a survey Caroline Gosselin ${ }^{* 1}$ and Guylaine Cote $^{2}$
}

Address: ${ }^{1}$ Department of Research and Development Mincavi, inc.51, Pinacle Rd, Danville, Qc, JoA 1Ao, Canada and ${ }^{2}$ Department of Anatomy and Physiology Faculty of Medicine, Laval University, Qc, G1K 7P4, Canada

E-mail: Caroline Gosselin* - gosselin.cabanac@sympatico.ca; Guylaine Cote - acc316@agora.ulaval.ca

*Corresponding author

This article is available from: http://www.biomedcentral.com/1472-6874/I/2

(C) $200 \mathrm{I}$ Gosselin and Cote; licensee BioMed Central Ltd. Verbatim copying and redistribution of this article are permitted in any medium for any noncommercial purpose, provided this notice is preserved along with the article's original URL. For commercial use, contact info@biomedcentral.com

\begin{abstract}
Background: After 5 years, most reports show that less than $10 \%$ of people maintain a $5 \%$ loss from initial body weight. Weight maintenance after 10 years is rarely assessed, especially in commercial programs. The current article reports weight maintenance in individuals who had participated 2 to II years earlier in a popular commercial weight loss program based on Canada's Food Guide called Mincavi.
\end{abstract}

Methods: Randomly picked subjects answered a telephone questionnaire. Participants, 29 I adult women from various regions of the province of Quebec, had followed the program 2 to II years earlier for at least a month. Body weight at the beginning and at the end of treatment was recorded as well as actual weight, age and height. Existing records allowed partial verification of the sample.

Results: Based on corrected weights, percentage of women who maintained at least $5 \%$ of their initial weight loss are as following; 2 years $=43.6 \%(n=55), 3$ years $=33.3 \%(n=42), 4$ years $=$ $23.8 \%(n=42), 5-6$ years $=38.2 \%(n=55), 7-8$ years $=29.4 \%(n=51)$, and $9-11$ years; $19.6 \%(n$ $=46$ ). Five to eleven years after they had participated in the program $29.1 \%$ of all women maintained a weight loss of at least $5 \%$, while $14.3 \%$ maintained a loss of at least $10 \%$.

Conclusions: Even though success rate is not as high as could be wished for, results show that participation in the Mincavi program can lead to effective weight maintenance long after individuals have left it. These findings suggest more thorough studies should be conducted on this weight loss program.

\section{Background}

Most studies assessing long-term weight loss maintenance have yielded disappointing long-term results, showing that almost all individuals regain lost weight after 3 to 5 years [1-6]. Follow-up on longer periods are rare, and tend to confirm that maintaining substantial weight loss is something that very few people achieve [710]. For example, Sarlio-Lahteenkorva and colleagues have recently reported that after 6 and 15-year followups, only $5,1 \%$ of all women maintained a loss of at least $5 \%$ of their baseline body weight [7].

The majority of these studies have been conducted on hospital and university weight loss programs. Because overweight individuals who seek treatment in such settings display more psychopathology and binge-eating 
[11], it has been proposed that such studies may have produced overly pessimistic conclusions [12].

All around the world, and especially in North America, commercial weight loss programs have been established in great numbers to help obese and overweight individuals. However, little is known about their long-term effectiveness. In a recent report assessing weight maintenance 1 to 5 years after a commercial program, Lowe et al. have shown that such programs can yield encouraging results [12].

The present paper reports weight maintenance in women 2 to 11 years after their participation in a popular commercial program in the province of Quebec, Canada. This program, called Mincavi (meaning "thin for life" in French), has been enforcing Canada's Food Guide recommendations since 1983 .

Upon entry in the program, participants, mostly women, receive a recipe book and are told about the importance of eating at least 3 meals a day and choosing from a variety of foods in the four major food groups (grain products, fruits/vegetables, milk/milk products, meat/meat alternate). Recipes are based on inexpensive, readily available whole grains products, vegetables and fruits, lean meats, low-fat dairy products and legumes. Participants decide themselves how much weight they want to lose.

Using a variety of nutritious, well balanced, familyfriendly meals, women and teenagers, in the weight loss phase, are taught to eat approximately $1400 \mathrm{kcal}$ a day and men, around $1800 \mathrm{kcal}$. During that phase, on average, $50 \%$ of the energy comes from carbohydrates, $25 \%$ from protein and $25 \%$ from lipids. In the maintenance phase, participants are encouraged to increase their caloric intake by $50 \mathrm{kcal}$ per week, in a minimum of 8 weeks, to eventually reach a daily intake of 1800 kcal for women and $2200 \mathrm{kcal}$ for men. During this second phase, diet composition changes slightly, with a decrease in protein and an increase in lipid content (carbohydrates:50\%, protein: $22 \%$, lipids: $27 \%$ ).

In groups of 50 to 100, participants are taught how to record everything they eat in diaries designed for that purpose and are invited to show them to their group leader every week for feed-back. Group leaders are women who have lost weight and kept if off for at least two years by following the Mincavi program. Weigh-in sessions followed by 30 to 45 minute-conferences on various topics (ex. weight loss, nutrition, motivation) and recipe sampling take place on a weekly basis. Additional support from a dietician and a psychologist is available through a toll-free phone line and internet.
Participating in the program involves a one-time fee of $25 \$$ (Canadian dollars), and a $7 \$$ fee per week during the weight loss phase. Once a participant has reached her goal weight, she is given free access to weekly sessions for as long as she maintains her goal weight. A fee of $7 \$$ will be charged on weighing sessions if she is found to have gained weight.

Modest losses such as $5 \%$ of initial body weight have been shown in the past decade, to induce significant health benefits such as improvements in lipid profile, glycemia, blood pressure, self-esteem and other health related indicators $[13-16]$. For that reason, maintenance of a $5 \%$ decrease from pre-treatment weight has been recognized in 1995 as the standard for success by the Institute of Medicine [17]. It was used here, as in other studies $[7,18]$ as the cut-off point to determine successful vs unsuccessful weight-maintainers.

\section{Methods}

\section{Subjects}

Two hundred and ninety one (291) women participated in the present study. Subjects were randomly picked using the company's list of clients. In order to assess longterm weight maintenance, only individuals who had entered the program at least 2 years earlier were contacted. Pregnant women at the time of interview and individuals who had followed the program for less than a month were excluded from the analysis.

\section{Data collection}

Subjects were contacted by telephone. Those agreeing to take part in the study, representing 90\% of the individuals contacted, were asked a series of questions. Age, height, date of entry in the program, body weight at the beginning of the program, amount of weight loss, and actual body weight, were noted. Body Mass Index (BMI) was calculated for each subject using height and beforeand after-treatment weight. Existing records allowed us to verify body weights, weight loss and height on $11 \%$ of the sample $(\mathrm{n}=31)$. Date of entry was available from records for all women $(n=291)$.

Since it has been demonstrated that people tend to underreport their actual body weight, especially if given by telephone, results were adjusted for the magnitude of the discrepancy. Tell and colleagues 19 have shown that on average, people reported a body weight $2.9 \%$ lower than the measured weight (mean $=2 \mathrm{~kg}$ ). A similar discrepancy was observed in our sample. For that reason, a 2.9\% increase in body weight was added to all subjects for whom present weight records were not available. 
Table I: Subjects characteristics. Average $( \pm$ SD) age, weight loss, BMI before, after the program and at follow-up and weight loss maintained in terms of percentage of initial body weight, are given here for the entire group, as well as for each follow-up category. When BMIs before the program and at follow-up are compared, a significant difference could be found only in the 2-year follow-up group ( $t=$ $2.919, P=0,0051)$.

\begin{tabular}{|c|c|c|c|c|c|c|}
\hline Follow-up & Age & $\begin{array}{l}\text { Weight loss } \\
\text { (kg) }\end{array}$ & $\begin{array}{c}\text { BMI before } \\
\text { program }\end{array}$ & $\begin{array}{l}\text { BMI after } \\
\text { program }\end{array}$ & $\begin{array}{c}\text { BMI at } \\
\text { follow-up }\end{array}$ & $\begin{array}{c}\text { Weight loss } \\
\text { maintained } \\
\text { (\% initial body weight) }\end{array}$ \\
\hline $\begin{array}{l}2 \text { years } \\
(\mathrm{n}=55)\end{array}$ & $43,3 \pm 12,7$ & $10,4 \pm 6,3$ & $30,6 \pm 4,5^{*}$ & $26,6 \pm 3,9$ & $29,2 \pm 5,0^{*}$ & $7,0 \pm 8,3$ \\
\hline $\begin{array}{l}3 \text { years } \\
(\mathrm{n}=42)\end{array}$ & $45,8 \pm 12,5$ & $12,2 \pm 7,6$ & $31,5 \pm 5,0$ & $27,0 \pm 4,1$ & $30,8 \pm 5,4$ & $4,5 \pm 6, I$ \\
\hline $\begin{array}{l}4 \text { years } \\
(n=42)\end{array}$ & $46,1 \pm 14,6$ & $10,2 \pm 5,8$ & $30,2 \pm 6,1$ & $26,3 \pm 5,9$ & $30,0 \pm 7,0$ & $3,4 \pm 5,5$ \\
\hline $\begin{array}{l}5-6 \text { years } \\
(n=55)\end{array}$ & $43,4 \pm 13,4$ & $10,6 \pm 7,0$ & $29,6 \pm 5,0$ & $25,5 \pm 3,5$ & $29,2 \pm 5,8$ & $4,7 \pm 6,3$ \\
\hline $\begin{array}{l}\text { 7-8 years } \\
(n=5 I)\end{array}$ & $40,4 \pm 13$ & $11,2 \pm 6,6$ & $28,0 \pm 3,4$ & $23,3 \pm 4, I$ & $28,5 \pm 4,8$ & $3,5 \pm 5,7$ \\
\hline $\begin{array}{c}\text { 9- } 11 \text { years } \\
(n=46)\end{array}$ & $39,8 \pm 9,7$ & $|2,8 \pm 9|$, & $29,3 \pm 3,8$ & $24,8 \pm 4,4$ & $29,7 \pm 4,5$ & $3,4 \pm 6,7$ \\
\hline $\begin{array}{l}\text { Entire group (2-I I yrs) } \\
\qquad(n=291)\end{array}$ & $43,0 \pm 12,8$ & $1 \mathrm{I}, 2 \pm 7,0$ & $29,8 \pm 4,7$ & $25 \pm 4,5$ & $29,5 \pm 5,4$ & $4,5 \pm 6,6$ \\
\hline
\end{tabular}

\section{Statistics}

Standard methods were used to calculate descriptive statistics and values are presented as means \pm SD. Analysis of variance (ANOVA) was used to analyze quantitative variables. Using the ANOVA table, a Bonferroni post hoc test was performed to examine comparisons between groups. Paired t-test was used to evaluate differences between BMIs before the program and at follow-up. For all tests, $\mathrm{p}<0.05$ was accepted as the significant level.

\section{Results}

\section{Subjects characteristics}

Mean age for the entire group was 43 yrs \pm 13 upon entry in the program. Mean BMIs before, after the program and at follow-up were respectively; 29.8 $\pm 4.7,25.5 \pm 4.5$ and $29.5 \pm 5.4$. When BMIs before the program and at follow-up are compared, a significant difference could be found only in the 2-year follow-up group $(t=2.919, \mathrm{P}=$ $0.0051)$. On average, subjects lost $11.1 \mathrm{~kg} \pm 7.1$ and at follow-up maintained a mean loss of $4.5 \% \pm 6.6$ of initial body weight. At time of follow-up, most subjects were no longer enrolled in the program with only 18 individuals still participating in it.

\section{Weight maintenance}

Two to eleven years (2-11 y) after participating in the program, $49.5 \%(n=144)$ of the women had either returned to their initial body weight or gained back additional weight, and $50.5 \%(n=147)$ weighed 1 to $32 \%$ less than at the beginning of the program. As can be seen on
Table 2, after 2 years, $43.6 \%$ of the subjects were found to maintain a weight loss of at least $5 \%$ of their initial body mass, whereas $29.1 \%$ maintained a loss of $10 \%$ or more. After 5-6 years, these numbers were respectively $38.2 \%$ and $16.4 \%$. Almost twenty percent (19.6\%) of subjects in the 9-11-year follow-up category maintained a weight loss of at least $5 \%$ of their initial mass while $10.9 \%$ were found to maintain a loss of $10 \%$ or more. Of the 18 subjects who were still enrolled in the program at followup, 12 (67\%) maintained a 5\% loss from initial body weight. Average loss maintained in that subset was a $16 \%$ decrease in body weight.

\section{Age}

Some studies have shown a positive correlation between age and weight maintenance 20 . In the present work, no correlation was found between the subjects' age at the beginning of the program and weight loss maintenance ( $\mathrm{P}=0.0651, \mathrm{~N} . \mathrm{S})$. However, the relatively narrow age spectrum represented among the Mincavi participants $(43 \pm 12,8)$ may limit the interpretation of the current results.

\section{Discussion}

The vast majority of weight loss programs reported in the literature show poor long-term efficiency. In the recent years however, a few studies have reported a relatively high level of weight maintenance. In the following section, methodological aspects of these studies are discussed in the light of our current results. 
Table 2: Percentage of subjects according to weight category at follow-up. Depending on their body weight at follow-up (2 to I I years after beginning the program), subjects are placed in the present table in categories ranging from "Heavier than before program" to "Weight loss of more than $\mathbf{2 5} \%$ of initial body weight". For each follow-up period, percentage of subjects who maintain a $5 \%$ or a $10 \%$ loss from initial body weight is indicated.

\begin{tabular}{|c|c|c|c|c|c|c|c|}
\hline Follow-up & $\begin{array}{c}\text { Same or } \\
\text { heavier than } \\
\text { before } \\
\text { program }\end{array}$ & $\begin{array}{c}\text { Weight loss } \\
0,1-4,9 \%\end{array}$ & $\begin{array}{c}\text { Weight } \\
\text { loss 5-9,9\% }\end{array}$ & $\begin{array}{c}\text { Weight } \\
\text { loss } \\
\text { 10-14,9\% }\end{array}$ & $\begin{array}{c}\text { Weight } \\
\text { loss I5\% or } \\
\text { more }\end{array}$ & $\begin{array}{c}\text { At least a } 5 \% \\
\text { weight loss }\end{array}$ & $\begin{array}{c}\text { At least a } 10 \% \\
\text { weight loss }\end{array}$ \\
\hline $\begin{array}{l}2 \text { years } \\
(n=55)\end{array}$ & $34,5 \%$ & $21,8 \%$ & $14,5 \%$ & $9,1 \%$ & $20,0 \%$ & $43,6 \%$ & $29,1 \%$ \\
\hline $\begin{array}{l}3 \text { years } \\
(n=42)\end{array}$ & $42,9 \%$ & $23,8 \%$ & $14,3 \%$ & $14,3 \%$ & $4,8 \%$ & $33,4 \%$ & $19,1 \%$ \\
\hline $\begin{array}{l}4 \text { years } \\
(\mathrm{n}=42)\end{array}$ & $52,4 \%$ & $23,8 \%$ & $11,9 \%$ & $4,8 \%$ & $7,1 \%$ & $23,9 \%$ & $11,9 \%$ \\
\hline $\begin{array}{l}5-6 \text { years } \\
(n=55)\end{array}$ & $50,8 \%$ & $10,9 \%$ & $21,8 \%$ & $9,1 \%$ & $7,3 \%$ & $38,2 \%$ & $16,4 \%$ \\
\hline $\begin{array}{l}7-8 \text { years } \\
(n=5 I)\end{array}$ & $58,9 \%$ & $11,8 \%$ & $13,7 \%$ & $11,8 \%$ & $3,9 \%$ & $29,4 \%$ & $15,7 \%$ \\
\hline $\begin{array}{c}9-11 \text { years } \\
(n=46)\end{array}$ & $58,7 \%$ & $21,7 \%$ & $8,7 \%$ & $2,2 \%$ & $8,7 \%$ & $19,6 \%$ & $10,9 \%$ \\
\hline $\begin{array}{l}2 \text { to II yrs (all subjects) } \\
\qquad(\mathrm{n}=29 \mathrm{I})\end{array}$ & $\begin{array}{c}49,5 \% \\
(n=144)\end{array}$ & $\begin{array}{c}18,6 \% \\
(n=54)\end{array}$ & $\begin{array}{c}14,4 \% \\
(n=42)\end{array}$ & $\begin{array}{c}8,6 \% \\
(n=25)\end{array}$ & $\begin{array}{c}8,9 \% \\
(n=26)\end{array}$ & $\begin{array}{l}31,9 \% \\
(n=90)\end{array}$ & $\begin{array}{c}17,5 \% \\
(n=48)\end{array}$ \\
\hline $\begin{array}{l}5 \text { to II years } \\
(n=152)\end{array}$ & $\begin{array}{l}56,1 \% \\
(n=85)\end{array}$ & $\begin{array}{l}14,8 \% \\
(n=22)\end{array}$ & $\begin{array}{l}14,7 \% \\
(n=23)\end{array}$ & $\begin{array}{c}7,7 \% \\
(n=12)\end{array}$ & $\begin{array}{c}6,6 \% \\
(n=10)\end{array}$ & $\begin{array}{l}29,1 \% \\
(n=45)\end{array}$ & $\begin{array}{l}14,3 \% \\
(n=22)\end{array}$ \\
\hline
\end{tabular}

\section{Sample characteristics}

Duration of treatment

An intensive weight loss program in Slovenia including behavioral, psychological, cognitive and physical elements has shown promising long-term results on 48 subjects [21]. Median weight loss of completers when they left the program was $11.5 \mathrm{~kg}$. At least 5 years later, 13 of them still maintained the reduced weight.

It is important to note that only participants who had successfully completed at least 4 months of treatment were included in the analysis. This criteria probably allowed selection of individuals already more successful or motivated than the ones who had quit the program after less than 4 months. In comparison, subjects were included in the present study after being enrolled for a minimum of one month in the Mincavi program representing the majority of individuals entering this program. In addition, it has been found that treatment duration is significantly correlated with weight loss after treatment and at follow-up - the longer the treatment, the better the results $-[22]$.

Nevertheless, results provided by this Slovanian general practitioner are valuable as his study implied regular follow-ups and weight measurements of participants for 5 years. His study also confirm the importance of a comprehensive approach in the treatment of obesity.

\section{Complementary treatment}

One of the rare studies on weight loss maintenance after 5 years has been conducted by Björvell and Rössner, a Swedish team. A 10-year follow-up has indicated a maintenance of weight losses averaging $10.5 \mathrm{~kg}$ after a 4 year continuous treatment [23]. However, in an earlier report, the authors have indicated that $36 \%$ of their subjects had their jaws fixed from the start, a factor than could have possibly enhanced the results [24].

\section{Selection of subjects}

A recent follow-up of individuals who had successfully completed a popular commercial program has shown that $42.6 \%$ of the subjects still maintained a $5 \%$ weight loss after five-year, while $18.8 \%$ maintained a loss of $10 \%$ or more [12]. These promising results suggest that some commercial programs can generate effective long-term results. It has to be kept in mind, however, that this study was conducted on successful participants who had reached their goal weight and achieved Lifetime Member status. As the authors state in their article, these individuals only represent a fraction of those who enter this particular commercial program. For that matter, it cannot be assumed that the rest of the participants who had only progressed part way to their goal would have demonstrated similar weight maintenance. 
Another such example is seen in a report on The Trevose Behavior Modification Program, a self-help weight loss program offering continuous care. Latner et al. have shown that members who had completed 5 years of the Trevose program were still $17.3 \%$ below their pre-treatment weight, showing considerable weight maintenance [25].

Again, it is important to note that the Trevose Program participants were selected upon entry and throughout the weight loss process, starting with 329 applicants and ending with 37 participants at the end of the 5-year treatment period. Therefore, only about a tenth of the participants, all highly motivated and successful at weight maintenance, were available for this particular analysis. This may explain, in part, such outstanding results.

However, even though efficient such continuous and strict treatments may not correspond to the needs and preferences of a majority of people. For example, failure to meet attendance or weight loss requirements results in immediate dismissal from the Trevose program with no possibility of re-entering it. Such programs may suit people who need a strict and highly structured environment to succeed but discourage those who need more flexibility.

\section{Body Mass Index at the onset of treatment}

It is known that larger weight losses are associated with greater weight maintenance because more weight is lost to begin with [25]. For that matter, average BMI of participants should be taken into account when comparing weight loss programs' efficiency. For example, average BMI at the onset of treatment was 41.5 for the Swedish program [24] and 34 for the Trevose program [25]. Participants of the Mincavi weight loss program were relatively light, with a mean BMI of 29.8 at the start of the program.

\section{Amount of weight loss}

Anderson and colleagues [20] have recently studied participants who had lost at least $10 \mathrm{~kg}$ through an intensive very-low-calorie diet. Forty percent (40\%) of their subjects maintained a weight loss of at least $5 \%$ of their initial body weight after a 5 -year follow-up $(n=112)$. In the present study, participants remained for analyses regardless of how little weight they had lost through the Mincavi program. Nevertheless, when only those women who had lost at least $10 \mathrm{~kg}$ were considered for a 5 to 6year follow-up ( $\mathrm{n}=43), 55.8 \%$ maintained such a weight loss.

In addition, mean weight loss of their subjects was 29.7 $\mathrm{kg}$, while among Mincavi's subjects who had lost at least $10 \mathrm{~kg}$, mean weight loss was only $12,0 \mathrm{~kg}$. As mentioned earlier, the greater the weight loss, the more frequent it has been shown to maintain a substantial portion of it over time.

\section{Other factors}

\section{Adjustment for self-reported information}

Among the few studies showing relatively high success rates after 3,5 or 10 years, three relied mostly on self-reported body weight $[20,23,26]$. In these three cases, discrepancy between self-reported and measured weight was not adjusted for, suggesting that weight maintenance may have been over-estimated for these programs.

\section{Effect of aging on weight maintenance}

An additional factor that needs to be taken into account when assessing long-term maintenance of lost weight is the effect of aging on body weight. It has been demonstrated that body weight set-point increases steadily with age in animals [27]. The same phenomenon is believed to exist in humans [28] making it increasingly difficult to maintain one's young adult body weight. It has been demonstrated that an average weight gain of $11 \mathrm{~kg}$ occurs between the age of 25 and 65 in women [28]. A decrease in energy expenditure is believed to contribute to this weight gain [29]. Therefore, some of the weight gain observed in longer follow-ups ( $>10$ years) could be attributed in part to the effect of aging rather than poor weight control. Consequently, it is possible that subjects who have returned to their initial body weight after a decade may in fact be leaner than what they would have been if they had not followed the weight loss program.

\section{Conclusion}

The present work is one of the rare existing studies on weight maintenance 10 years following a weight loss program, whether commercial or not. Another unique feature of the current report is that subjects were included in the study whether they had reached their goal weight or not while in the program. By doing so, results provide a picture of long-term weight maintenance in most individuals who enter this particular commercial program rather than focusing on successful individuals only.

Limitations of the present study include a small number of subjects in each follow-up category. While the initial number of participants is decent at 291, the subsets that are subsequently used in the analysis become small, thus eroding confidence in the results. Another limitation of this study is the use of self-reported data. Because the present work relied mostly on such data, interpretation calls for caution. For that matter, it was necessary to adjust for the discrepancy often seen between self-reported body weight and measured weight. 
Once corrected, results show that 5 to 11 years after the program, 29\% of women still maintained a weight loss of at least $5 \%$ of their initial weight $(n=45)$. While lower than what could be wished for, these results are more encouraging than those generally found in the literature.

These preliminary results suggest that Mincavi, a weight loss program that encourages participants to eat a variety of nutritious, well-balanced, family-friendly meals, can be a useful tool for the long-term treatment of overweight and obese individuals. Prospective studies involving a greater number of subjects and repeated measures of body weight should be conducted in order to better assess long-term effectiveness of the Mincavi program and understand factors contributing to weight maintenance.

\section{Declaration of competing interests}

Have you received reimbursements, fees, funding, or salary from an organization that may in anyway gain or lose financially from the publication of this paper in the past 5 years? If so, please specify.

Yes. Dr Gosselin is now scientific manager of the company. However, at the time the present study was conducted she was at the Faculty of Medicine of Sherbrooke University and not employed nor funded by Mincavi. No such competing interests for Ms. Cote.

Have you held any stocks or shares in an organization that may in any way gain or lose financially from the publication of this paper? If so, please specify.

No, for both authors.

Do you have any other competing interests? If so, please specify.

No, for both authors.

Are there any non-financial competing interests you would like to declare in relation to this paper?. If so, please specify.

No, both authors.

\section{Acknowledgements}

The authors would like to thank Lyne Martineau and Caroline M. Gauthier, president and vice-president of Mincavi inc., as well as Véronique Gilbert, $\mathrm{BSc}$, Danielle Dubois, Dtp and the Mincavi group leaders for their valuable assistance.

\section{References}

I. Stunkard AJ, Penick SB: Behavior modification in the treatment of obesity: the problem of maintaining weight loss. Arch. Gen. Psychol 1979, 36:801-806

2. Stalonas PM, Perri MG, Kerzner AB: Do behavioral treatments of obesity last? A five-year follow-up investigation. Addict. Behav 1984, 9:175-83
3. Wadden TA, Sternberg JA, Letizia KA, Stunkard AJ, Foster GD: Treatment of obesity by very low caloric diet, behavior therapy, and their combination: a five-year perspective. Int. J. Obes 1 989, I 3:39-46

4. Wadden TA, Frey DL: A multicenter evaluation of a proprietary weight loss program for the treatment of marked obesity: a five-year follow-up. Int. J. Eat. Dis. 1997, 22:203-2I 2

5. Glenny AM, O'Meara S, Melville A, Sheldon TA, Wilson C: The treatment and prevention of obesity: a systematic review of the literature. Int. J. Obes. Relat Metab Disord 1997, 2 I:715-737

6. Crawford D, Jeffery RW, French SA: Can anyone successfully control their weight? Findings of a three year communitybased study of men and women. Int. J. Obes. Relat Metab Disord 2000, 24:1107-1 I10

7. Sarlio-Lahteenkorva S, Rissanen A, Kaprio J: A descriptive study of weight loss maintenance: $\mathbf{6}$ and $\mathbf{5}$ year follow-up of initially overweight adults Int. J. Obes 2000, 24(I): I I 6-I25

8. Dwyer JT, Lu D: Popular diets for weight loss : from nutritionaly hazardous to healthful. In: Stunkard, AJ, Wadden, TA (eds). Obesity: Theory and Therapy. 2nd ed. Raven Press Itd: New York, NY. I99323 I251

9. Miller WC: How effective are traditional dietary and exercise interventions for weight loss? Med. Sci. Sports Exerc 1999, 3 I:I I29-I I34

10. Jeffery RW, Drewnowski A, Epstein LH, Stunkard AJ, Wilson GT, Wing RR, Hill DR: Long-term maintenance of weight loss: current status. Health Psychol. 2000, I9(supp I):5-16

II. Fitzgibbon ML, Stolley MR, Kirschenbaum DS: Differential characteristics of obese individuals who do or do not seek treatment. Health Psychol 1993, I 2:342-345

12. Lowe MR, Miller-Kovach K, Phelan S: Weight loss maintenance in overweight individuals one to five years following successful completion of a commercial weight loss program. Int. J. Obes. Relat Metab Disord 200I, 25:325-33I

13. Goldstein DJ: Beneficial health effects of modest weight loss. Int. J. Obes. Relat Metab Disord 1992397-4I5

14. Kanders BS, Blackburn GS: Reducing primary risk factors by therapeutic weight loss. In: Treatment of the seriously obese patient, TA Wadden, TB Vanltallie (eds). Guilford Press: New York. 19922 I3-231

15. Pi-Sunyer FX: Short-term medical benefits and adverse effects of weight loss. Ann. Inter. Med 1993, I I 9(7 pt):722-726

16. Tremblay A, Doucet E, Imbeault P: Physical activity and weight maintenance. Int. J. Obes 1999, 23(supp 3):S50-S54

17. Institute of Medicine: Weighing the options. Washington, DC: National Academy Press, 1995

18. Grodstein F, Levine R, Troy L, Spencer T, Colditz GA, Stampfer MJ: Three-year follow-up of participants in a commercial weight loss program. Can you keep it off? Arch. Intern. Med. 1996, 156:1302-1306

19. Tell GS, Jeffery RW, Kramer FM, Snell MK: Can self-reported body weight be used to evaluate long-term follow-up of a weight loss program? J. Am. Diet. Assoc. 1987, 87: I 198-20।

20. Anderson JW, Vichitbandra S, Qian W, Kryscio RJ: Long-term weight maintenance after an intensive weight-loss program. J. Am. Coll. Nutr 1999, I 8(6):620-627

21. Kolsek M: Long term results of intensive treatment of obesity in the health centre Litija, Slovenia: a clinical audit. Int. J. Obes. Relat Metab Disord 1999, 23:702-705

22. Bennett GA: Behavior therapy for obesity: a quantitative review of the effects of selected treatment characteristics on outcome. Behav. Therap 1986, I 7:554-562

23. Björvell $\mathrm{H}$, Rössner $\mathrm{S}$ : A ten year follow-up of weight change in severely obese subjects treated in a behavioural modification-like program. Int. J. Obes Relat Metab Disord 1990, I 4(2):88

24. Björvell $H$, Rössner S: Long term treatment of severe obesity: four year follow up of results of combined behavioural modification programme. Br. Med. J.(Clin Res Ed) 1985, 29 I:379-382

25. Latner JD, Stunkard AJ, Wilson GT, Jackson ML, Zelitch DS, Labouvie $\mathrm{E}$ : Effective long-term treatment of obesity: a continuing care model. Int. J. Obes.Relat Metab Disord 2000, 24:893-898

26. Hylander B, Rössner S: Three years' follow-up of members of a Swedish commercial weight-reducing club. Acta Med. Scand. | 981, 2 1 0:485-488

27. Gosselin C, Cabanac M: Ever higher: constant rise of body weight set-point in growing Zucker rats. Physiol. Behav. 1996, 60:8|7-2| 
28. Hervey GR: Regulation of energy balance. Nature 1969, 223:62931

29. Anderson EJ, Lavoie HB, Strauss CC, Hubbard JL, Sharpless JL, Hall JE: Body composition and energy balance: lack of effect of shortterm hormone replacement in postmenopausal women. Metabolism 200I, 50:265-269

\section{Pre-publication history}

The pre-publication history for this paper can be accessed here:

http://www.biomedcentral.com/content/backmatter/ 1472-6874-1-2-b1.pdf

Publish with BioMed Central and every scientist can read your work free of charge

"BioMedcentral will be the most significant development for disseminating the results of biomedical research in our lifetime." Paul Nurse, Director-General, Imperial Cancer Research Fund

Publish with BMC and your research papers will be:

- available free of charge to the entire biomedical community

- peer reviewed and published immediately upon acceptance

- cited in PubMed and archived on PubMed Central

- yours - you keep the copyright 